\title{
About the certification of railway rails
}

\author{
A. De Iorio, M. Grasso, F. Penta, G.P. Pucillo \\ Università di Napoli Federico II, Dipartimento di Ingegneria Industriale, P.le V. Teccbio 80 - 80125 Napoli, Italy \\ antdeion@unina.it
}

\begin{abstract}
When the compliance with the European Code of some rail steel has to be verified, the need of carrying out the experimental activities in accordance with several testing Standards forces the operator both to solve the problems related to the choice of a suitable testing practice and often to interpret subjectively Standards guidelines. This does not facilitate the comparability and/or the quality of the results produced by several laboratories. With reference to a series of fatigue, fracture toughness and fatigue crack growth tests carried out by the authors on specimens extracted from rails, the main lacks in the current standards, related to both the choice of the control parameters and the testing procedures, are pointed out. Regarding the crack growth testing, several procedures to compute the crack growth rates to be compared with the limits prescribed by the Code are proposed. These procedures have been applied to a data set produced during the aforementioned testing activity, in order to highlight, by comparison of the results obtained by them, the significant differences in the crack growth rate estimates and the magnitude of the errors that can be done due to the lacks in the standard practices currently adopted.
\end{abstract}

KEYWORDS. Railway rail steel; Crack growth testing; Fatigue crack propagation; Raw data analysis; Fatigue damage; Railway certification.

\section{INTRODUCTION}

$\mathrm{D}$

uring the last decade the methods and central ideas of damage tolerance design raised an increasing interest from railway researchers, in particular concerning the service life and crack inspection of rails [1-4], since there are still many unresolved technical problems and intensely debated scientific issues.

In example, the demand of verifying that a rail steel meets also the fatigue crack growth requirements established by current regulations [5] making it able to be put to use, imposes that the operators pay the maximum attention in carrying out both the experimentation and the analysis of results, due to the high technical and commercial importance that the outcomes of these activities have. Since the testing procedures are defined by the Standards and the Standards have always to be fulfilled, it is very common considering, also among the insiders, this problem trivial or even out of place. However, the scatter in the experimental data and the possible anomalies in the results, which often are unpredictable and/or uncontrollable and are caused by the testing equipment, the control of testing parameters and the analysis of experimental data, do not allow identifying unambiguously the testing outcome. More specifically, with regard to the fatigue crack growth tests, it is not possible to compute directly the particular crack growth rate value to be compared with the reference value prescribed by the Code, to establish if the rail steel can be qualified for the use. Also in the case of the other rail qualification tests, current Standards do not seem to be enough robust to guarantee the comparability and reproducibility of the experimental results, since they are significantly dependent also on the free interpretation of rules or procedures not univocally or clearly defined. In this paper, the main phases of a complete series of certification tests on a 
rail steel are reported, in order to point out the aforementioned problems and for describing the solutions adopted as well as the detailed procedures that can be used to fill the gap left by the current Standards.

\section{EXPERIMENTAL ACTIVITY}

7 he testing activity has been carried out at the Mechanics of Materials and Structures Laboratory - Department of Industrial Engineering of Federico II University. Test articles were obtained from n.7 line production batches of rail 60E1 steel grade R260 manufactured by Manoir Industries Outreau (France). The exact composition of the steel used in the current investigation cannot be given, however it is within the composition range reported in the UNI EN 13674-1:2011. Among all tests prescribed by the Standard to qualify the rail steel, only fatigue tests, fracture toughness tests and fatigue crack growth tests have been carried out in the Department Lab.

For each batch, the specimens were extracted from n.2 rail sections (Fig. 1) and marked in accordance with recommendations of ref. [5].
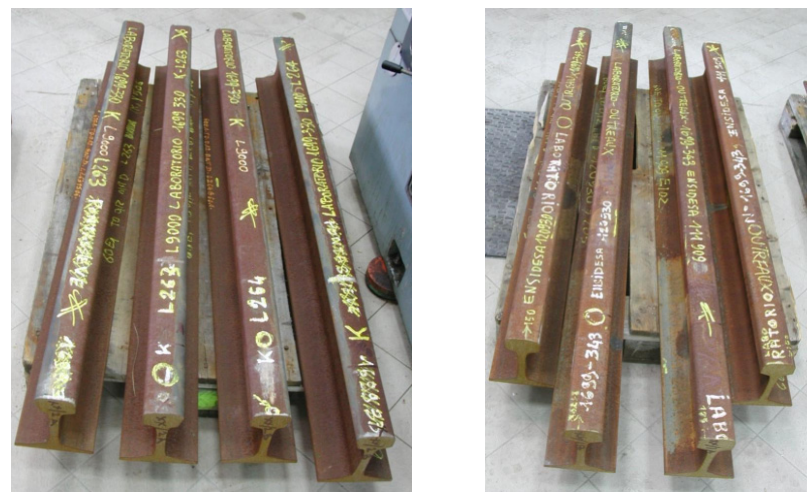

Figure 1: Rail sections from which specimens have been extracted.

\begin{tabular}{c|cc}
\hline Type of test & Number of tests & UNI EN 13674-1:2011 \\
Fatigue & 3 & par. 8.4 \\
Fatigue crack growth rate & 3 & par. 8.3 \\
Fracture toughness & 5 & par. 8.2 \\
\hline
\end{tabular}

Table 1: Number of samples for each type of test and corresponding paragraph in the Standard.

The geometry of some specimens employed for the tests are shown in Fig. 2.
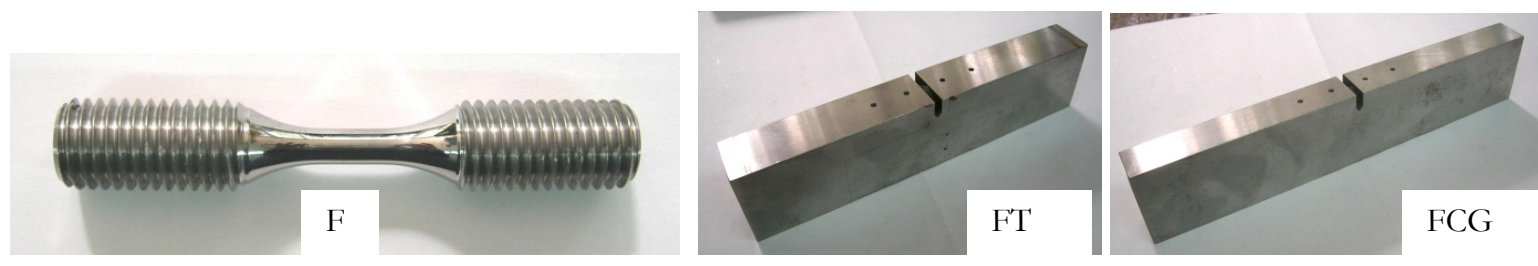

Figure 2: Specimens prototypes used for the testing activity.

\section{FATIGUE TESTS}

$\mathrm{F}$ or each material batch, according with the requirements of the UNI Standard [5], n.3 cylindrical specimens (Fig. 2, F), have been tested after having preliminarily inspected their surface with a 30x microscope (instead of the 20x prescribed by the Standard) to verify that any circumferential scratch within the specimen gauge length was absent. 
Tests have been carried out under strain control with strain ratio $\mathrm{R}=-1$ on a digitally controlled universal testing machine that was programmed to stop cycling after $5 \times 10^{6}$ cycles, as prescribed by the Standard.

Before starting the fatigue testing activities, two problems arose: the first one was related to the test control parameter, the second to the definition of the value to be assigned to it. Regarding the controlled parameter, the UNI EN 13674 requires that fatigue tests have to be carried out under strain control, applying a "total strain amplitude" equal to $1350 \mu \mathrm{m} / \mathrm{m}$, while for all other needed information related to the experimental set-up and testing procedure the ISO 1099 [6] is invoked even if this Standard concerns fatigue testing under stress control. The ISO Standard to be adopted for testing under strain control is instead the ISO 12106 [7].

Concerning the value to be assigned to the controlled parameter, namely the stress amplitude, $\sigma_{a}$ or $\mathrm{S}_{\mathrm{a}}$, the ISO 1099, after having defined it as "one-balf the algebraic difference between the maximum stress and the minimum stress in a stress cycle", in the same figure referred by the definition, identifies it as the stress range, called "stress amplitude $\Delta \sigma_{\mathrm{a}}$ ".

Thus, the correct interpretation of the Standards should lead to the choose of the strain amplitude as controlled parameter for fatigue tests and to a value of the total strain range equal to twice the reference amplitude value of $1350 \mu \mathrm{m} / \mathrm{m}$ defined in the UNI EN.

The aforementioned ambiguity misled well-known qualified laboratories that carried out tests using strain amplitude equal to half of the prescribed value.

A further basic problem related to the adoption of the correct strain amplitude value was the failure of the screw end of the specimens in the last thread engaged with the sleeve of the test fixture caused by the high stress concentration at the root of the coarse thread, that had geometry in accordance with the Standards UNI EN 13674 and was obtained by turning (Fig. 3).

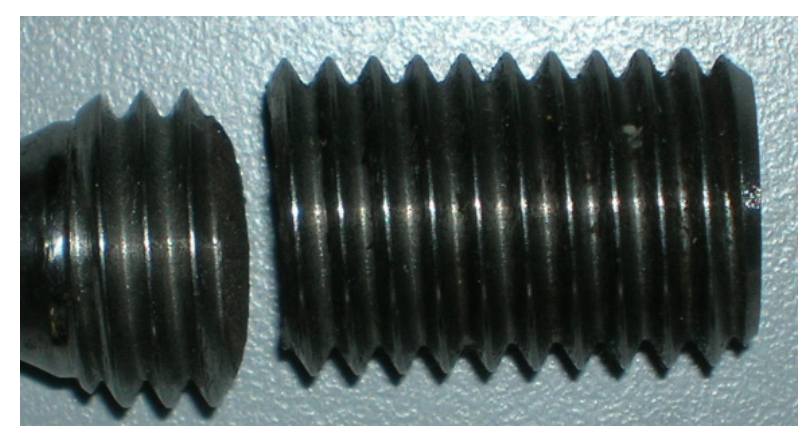

Figure 3: Fractured head of a fatigue specimen.

Since the specimens were already manufactured, this problem has been overcome making more gradual the way the load was transferred from the fixture to the specimen. However, it could be more easily avoided simply choosing a fine tread for the heads of the specimens, during the scheduling phase of the tests.

By means of the aforementioned solutions and Standard interpretations previously described, all fatigue tests have been carried out without further problems, anomalies or premature specimen failures.

\section{FRACTURE TOUGHNESS TESTS}

$\mathrm{F}$ or each production batch, n.5 fracture toughness tests at low temperature $\left(\mathrm{T}=-20{ }^{\circ} \mathrm{C}\right)$ were carried out in accordance with the UNI EN [5]. SEN(B) specimens having a chevron notch and thickness equal to $25 \mathrm{~mm}$ (Fig. 2, FT) were used. Experimental set-up and testing conditions complied with the prescriptions of the UNI EN 13674, Annex B whereby the ASTM E 399 [8] is referenced for all other information not specified in the UNI Standard. Since the UNI [5] gives limited guidelines and the ASTM [8] has a quite wide range of applicability and does not consider specifically tests at low temperature, it was necessary to overcome many drawbacks to define the testing procedure to be adopted. For this reason, it is not possible to find in it clear and unambiguous data about both the stepped load shedding procedure to be adopted during the precracking phase, the notch geometry, the notch machining method, the way the prescribed temperature $\left(\mathrm{T}=-20^{\circ} \mathrm{C}\right)$ has to be reached before test and, finally, the parameter to be controlled, since the tests may be carried out either under position control, according to the UNI [5], or under loading control, as reported in the ASTM [8]. Due to all these uncertainties, a significant randomness has to be expected in toughness tests results that can lead to erroneous conclusions or even compromises the certification of the rail steel. 
The adopted solutions for these tests, whose results are reported in Tab. 2 in term of mean value and standard deviation of each production batch, are:

I. Experimental set-up and stress ratio value $(\mathrm{R}=0.1)$ of the fatigue loading, are those prescribed by the UNI EN 13674, but regarding the precracking procedure and the other recommendations that are not considered in this standard, it was necessary to refer to the ASTM E399. This latter, being totally general, does not provide any specific indication regarding the maximum value of the fatigue load to be applied during the crack nucleation phase. It defines only the way the load maximum value has to be reduced by step (without exceeding $10 \%$ of the load maximum value reached in the previous step) and the minimum crack length increment of each step $j$ of load shedding, which has to be computed as:

$$
\Delta a_{j}=\left[\frac{K_{M A X}(j-1)}{\mathrm{R}_{p 0,2}}\right]^{2}
$$

Moreover, the Standard [5] prescribes that the ratio a/W at the end of the pre-cracking phase has to be in the range $0.45 \div 0.55$ as well as in the last $1.25 \mathrm{~mm}$ of crack growth the $\mathrm{K}_{\max }$ value has to be in the range $18 \div 22 \mathrm{MPa} \sqrt{\mathrm{m}}_{\text {. }}$ On the basis of these data, it was possible to define the load spectrum adopted for the whole precracking phase in terms of maximum applied loads (Fig. 4).

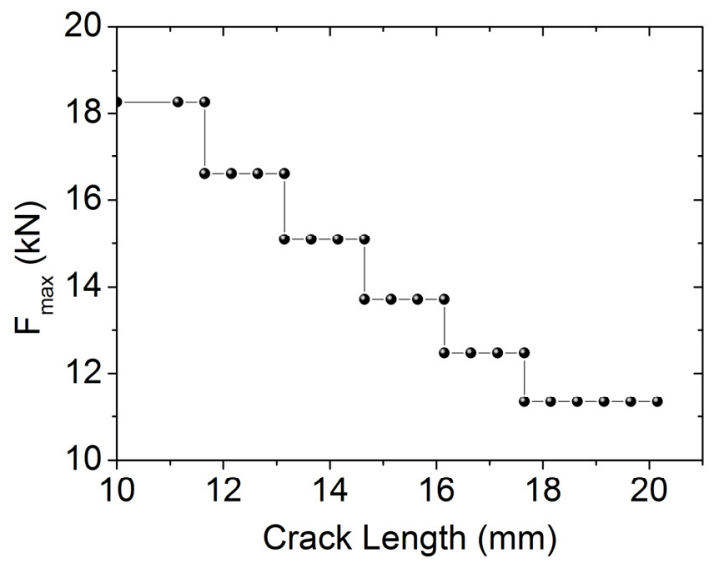

Figure 4: Load spectrum for the precracking phase.

\begin{tabular}{ccc}
\hline Batch & $\mathrm{K}_{\mathrm{Q}}(\mathrm{mean})\left(\mathrm{MPa}{ }_{\mathrm{m}}\right)$ & Standard Dev. $\left(\mathrm{MPa} \sqrt{\mathrm{m}}_{\mathrm{m}}\right)$ \\
$\mathrm{A}$ & 37.41 & 5.31 \\
$\mathrm{~B}$ & 39.42 & 6.64 \\
$\mathrm{C}$ & 35.20 & 4.58 \\
$\mathrm{D}$ & 33.08 & 2.55 \\
$\mathrm{E}$ & 31.35 & 0.59 \\
$\mathrm{~A} 1$ & 37.26 & 7.49 \\
$\mathrm{~B} 1$ & 38.35 & 2.32 \\
\hline
\end{tabular}

Table 2: Mean and standard deviation of the $\mathrm{K}_{\mathrm{Q}}$ values.

II. The chevron notch, whose depth on the specimen lateral faces was equal to $10 \mathrm{~mm}$ and whose width $b$ was equal to 5 $\mathrm{mm}$, was obtained by electro-discharge machining. The ASTM E399 also allows other machining methods to create the notch, even though they can be responsible of strong differences in the behaviour of the specimens during the crack nucleation phase, since a uniform quality of machining cannot be obtained along the whole chevron notch root.

III. To take the specimen to the temperature of $-20^{\circ} \mathrm{C}$, which is the value prescribed from the Standard [5], initially the temperature inside the environmental chamber was reduced to $\mathrm{T}=-50{ }^{\circ} \mathrm{C}$, monitoring the specimen temperature during this phase. When a value equal to $-15{ }^{\circ} \mathrm{C}$ was reached, a warming ramp was applied until the temperature inside the chamber was $-25^{\circ} \mathrm{C}$ and the specimen temperature was stabilized on the test value of $-20^{\circ} \mathrm{C}$. 
IV. Final quasi-static tests, to cause specimens fractures, were carried out under position control, with a loading rate equal to $0.0083 \mathrm{~mm} / \mathrm{s}$ and acquiring at a frequency of $50 \mathrm{~Hz}$ the output signals of both the load cell and the COD gauge needed to determine the $K_{\mathscr{Q}}$ value.

\section{FATIGUE CRACK GROWTH TESTS}

$\mathrm{F}$ atigue crack growth tests were carried out on n. 3 specimens obtained from each material batch, according to the UNI EN 13674. SEN(B) specimens having a chevron notch obtained by electro-discharge machine and thickness equal to $20 \mathrm{~mm}$ were used. After the dimensional checks, all specimens were instrumented with crack gauges applied on both lateral specimen faces to monitor and acquire the growth of the crack. However, when the crack grew in the chevron notch, COD gauge has been used to monitor its depth. Acquiring also the COD increments $\Delta V$ 's as function of the number of cycles proved to be useful even for determining the crack depth threshold value corresponding to the condition of emerging crack on one of the two specimen faces, being the only number of applied load cycles completely insufficient to detect this particular condition, due to its high dependency on the local geometry and microstructure of the material near the chevron notch root.

Experimental set-up was in accordance with the Qualification Standard [5], but the precracking procedure was defined as for the fracture toughness tests obtaining the load spectrum represented the diagrams of Fig. 5 both in term of the load maximum value and the corresponding SIF ranges.
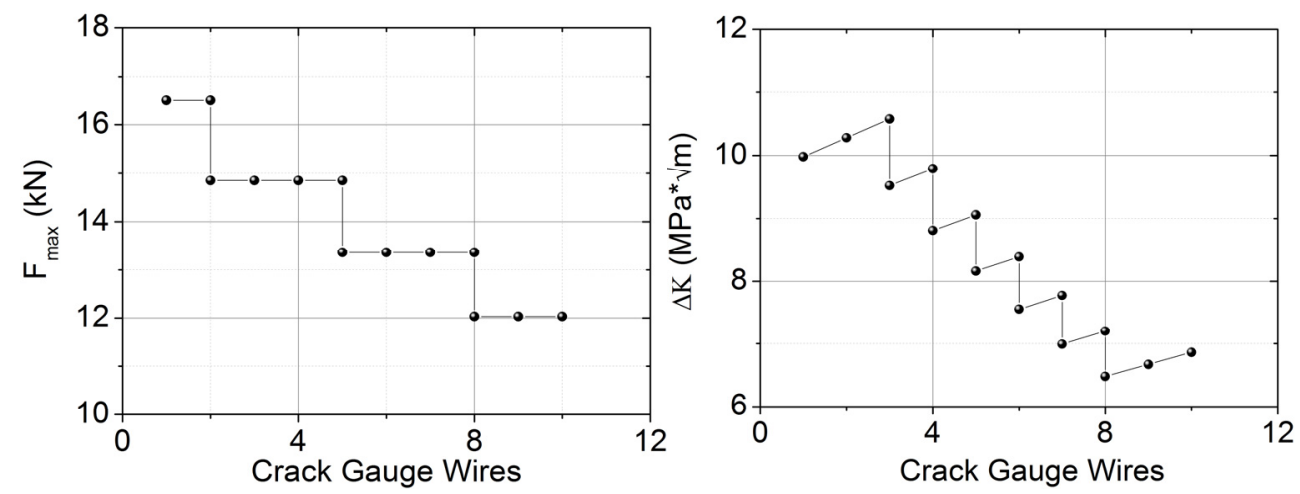

Figure 5: Precracking load spectrum of the FCG tests.

Since the stepped load shedding procedure is quite complex, researchers often prefer to carry out the test with a single loading level for the whole test, applying during the pre-cracking phase a stress ratio $\mathrm{R}=0.1$, so as to reduce its duration, instead of $\mathrm{R}=0.5$, that is the value prescribed by the Certification Standard [5] for the fatigue crack propagation tests. However, this approach even if it is not in contrast with the prescriptions of the Standards [BS [9] and UNI [5]], it is not in accordance with the guidelines reported in the ASTM E647 [10].

Moreover, passing from the precracking to the propagation phase, the crack growth rate could be less than that would occur if a stress ratio equal to 0.5 was used from the beginning of the test, since with $R=0.1$ the loading range would be higher and, consequently, the plastic region ahead the crack tip would be more extended. Concerning these aspects, the ASTM E647 recommends to adopt the same values of the $\mathrm{R}$ ratio for the whole test duration or, when $\mathrm{R}$ changes are needed, to increment the load maximum value in order to avoid retardation effects due to an extended plastic region at the crack tip.

Regarding the analysis of results, it has been observed that Standards do not give any guidelines about the procedure to be used to evaluate the required crack growth rates, corresponding to the two particular SIF range values: $10 \mathrm{MPa} V \mathrm{~m}$ e 13.5 $\mathrm{MPa} V_{\mathrm{m}}$, that have to be compared with the minimum values equal to $17 \mathrm{~m} / \mathrm{GC}$ and $55 \mathrm{~m} / \mathrm{GC}$, respectively, prescribed by the Certification Standard [5].

On the other hand, whichever would be the chosen maximum load value, it is never possible to carry out the tests in such a way that the analysis of the results gives the required exact $\Delta \mathrm{K}$ values. Furthermore, when a single maximum load value is adopted for the whole test, the applied $\Delta \mathrm{K}$ range could not include one of the two reference values. For this reason, it is necessary to evaluate the crack growth rate values by an ad hoc interpolation and extrapolation method of the raw data, which has to be fully defined due to the lack in the reference Standards. Obviously, as fully discussed in the following 
section, the crack growth rate values are affected also by the method adopted to evaluate them, thus it would be desirable that this lack in the Standard would be soon fill in the near future.

A synthetic list of the possible procedures that could be adopted to evaluate the crack growth rates is reported in the following.

a. Raw data in term of crack length versus number of cycles, collected during tests carried out under the K-increasing condition, are analysed by means of the 7-points Incremental Polynomial Method [10]. The discrete points $\Delta \mathrm{K}$ $\mathrm{da} / \mathrm{dN}$ obtained by this method are locally interpolated using either a second or a third order polynomial function. The crack growth rate values to be compared with the reference limits reported in the Standard are evaluated by the fitting polynomial function.

b. Raw data produced under the K-increasing condition are interpolated using the three-parameters model [11]. By sampling the model, it is possible to obtain a significant number of pairs of values $(a, N)$ in the suitable ranges including the reference $\Delta \mathrm{K}$ values. These pairs can be analysed as for the previous point.

c. The same raw data are interpolated using the three-parameters model, so by means of the derivative of the fitting function it is possible to compute the crack growth rate values corresponding to a significant number of crack length values, $a$. Then, the computed crack growth rates together with the corresponding $\Delta \mathrm{K}$ values are fitted using either a second or a third order polynomial function in order to obtain the rate values to be compared with the limits of the Standard.

d. Raw data produced under the K-increasing condition are interpolated using the three-parameters model and the derivative of the fitting function is evaluated. By means of its analytical expression it is possible to evaluate the crack growth rate values for the crack lengths corresponding to the prescribed $\Delta \mathrm{K}$ values. Since the testing conditions and the specimen geometry are known, by means of the expression of $\Delta \mathrm{K}$ it is possible to evaluate the geometry function $\mathrm{g}(\alpha)$ of the SEN(B) SIF expression, and to obtain the corresponding $\alpha$ values by one of the following methods:

- solving the equation obtained by substituting the computed $g(\alpha)$ value in the following expression

$$
g(\alpha)=\frac{6 \sqrt{\alpha}}{(1+2 \alpha)(1-\alpha)^{\frac{3}{2}}}\left[1.99-\alpha(1-\alpha)\left(2.15-3.93 \alpha+2.7 \alpha^{2}\right)\right]
$$

- computing the $\alpha$ value using the following equation:

$$
\alpha=\frac{0.0004464 g(\alpha)^{3}+0.9019 g(\alpha)^{2}-6.597 g(\alpha)+11.7}{g(\alpha)^{2}-1.017 g(\alpha)-14.01}
$$

Eq. (3) is the best fitting function of the pairs $\alpha-g(\alpha)$, computed using the geometry function (2) in the range $0.2<\alpha<0.85$. It has been determined by the least squares method and has coefficient of determination $\mathrm{R}^{2}$ equal to 1 . In both cases, by the $\alpha$ values it is possible to compute the corresponding crack lengths and, finally, the crack growth rates by the equation.

$$
\frac{d a}{d N}=\frac{(c+\gamma) \beta \alpha}{N_{f}\left(e^{\frac{\ln \left(\frac{c+\gamma}{a}\right)}{\beta}}\right)^{\beta+1}}
$$

e. In order to give with a more comprehensive overview on the procedures employed for rail steel certification, a further practice to evaluate the crack growth rate, widely adopted by some qualified laboratories, is reported. All $\Delta \mathrm{K}$ and $\mathrm{da} / \mathrm{dN}$ values, computed using the experimental data, are employed to estimate the $C$ and $m$ constants of the Paris model. Then, the Paris equation is used to evaluate the crack growth rates to be compared with the limits prescribed by the Standard.

\section{Procedures COMPARISON}

$\mathrm{I}$ $\mathrm{n}$ order to highlight analogies and differences among the proposed procedures, some crack growth data obtained by the authors and reported in Fig. 6 and corresponding to one of the two faces of the specimen KDP_1 are analysed. 


\section{Procedure I}

Adopting the procedure described in the appendix X1.2 of the ASTM E647, the crack growth rates and the corresponding $\Delta \mathrm{K}$ values were computed (Fig. 7).

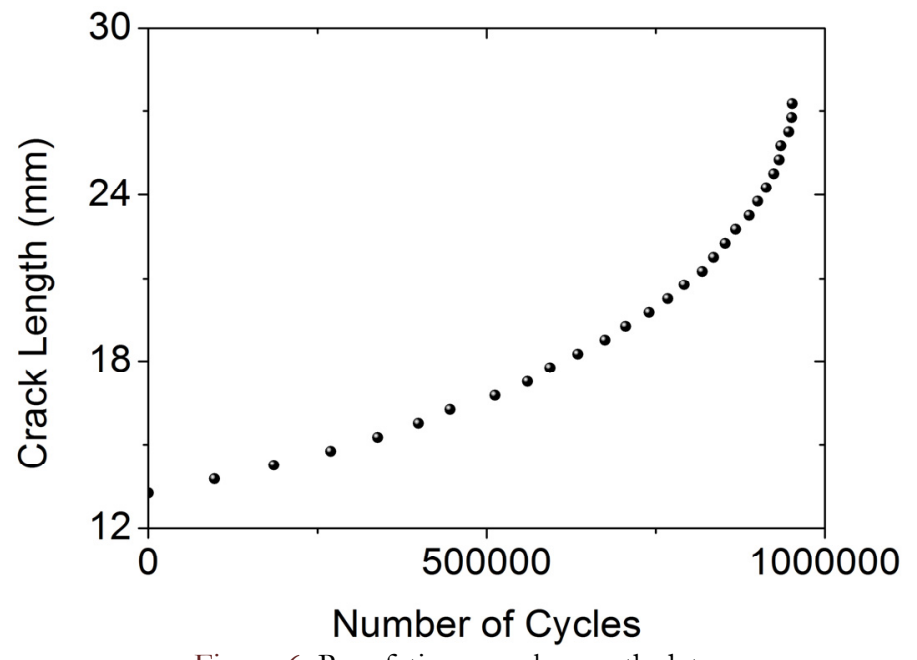

Figure 6: Raw fatigue crack growth data.

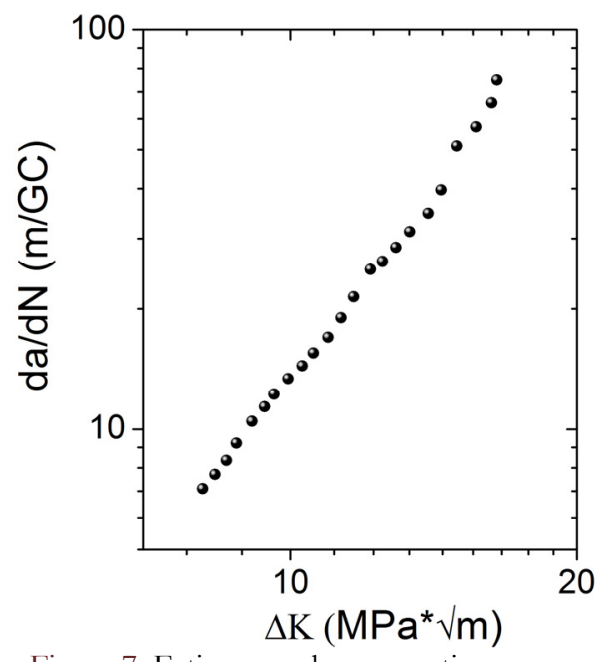

Figure 7: Fatigue crack propagation curve.

The crack growth rates are computed by means of local fitting of the raw data using either a second order or a third order polynomial function (Fig. 8 and 9). For each fitting n. $6 \Delta \mathrm{K}$ values in the neighbourhood of the references values have been chosen. A less number of points could result in a poor fitting.

\begin{tabular}{ccc}
\hline & $\Delta \mathrm{K}$ & $\begin{array}{c}\mathrm{da} / \mathrm{dN} \\
(\mathrm{m} / \mathrm{GC}) \\
(\mathrm{MPa} \sqrt{\mathrm{m}})\end{array}$ \\
Second order polynomial function & 10 & 13.49 \\
Third order polynomial function & 13.5 & 31.88 \\
& 10 & 31.75 \\
\hline
\end{tabular}

Table 3: Crack growth rate computed using the procedure $I$.
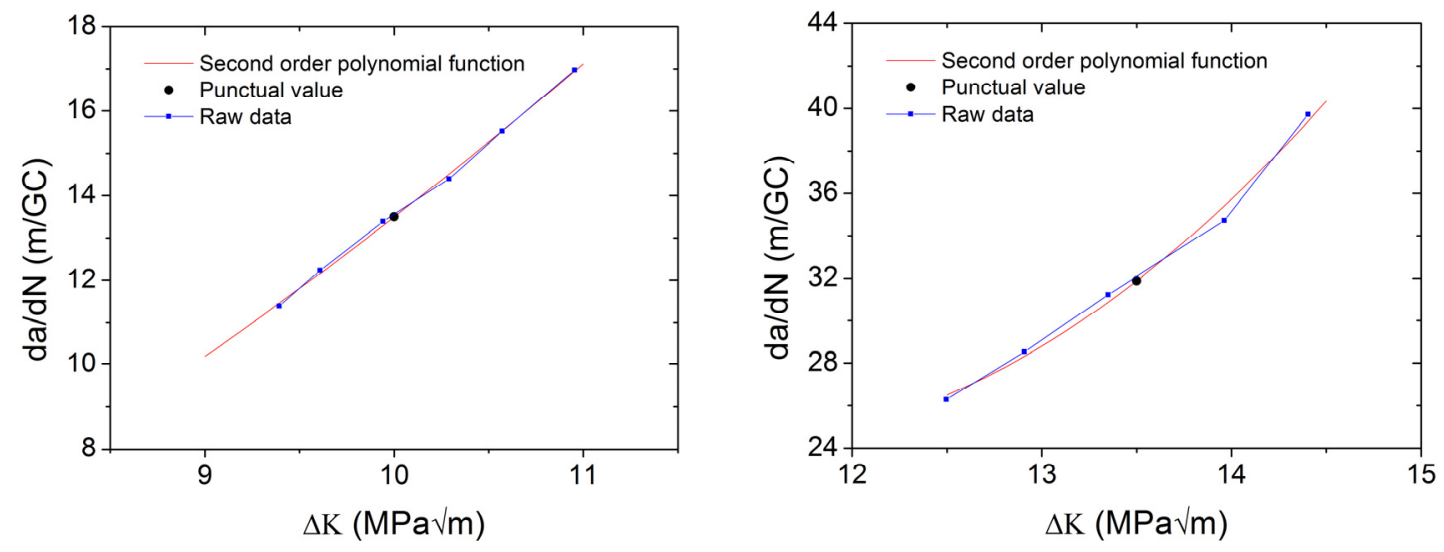

Figure 8: Second order polynomial fit of the crack growth rates. 

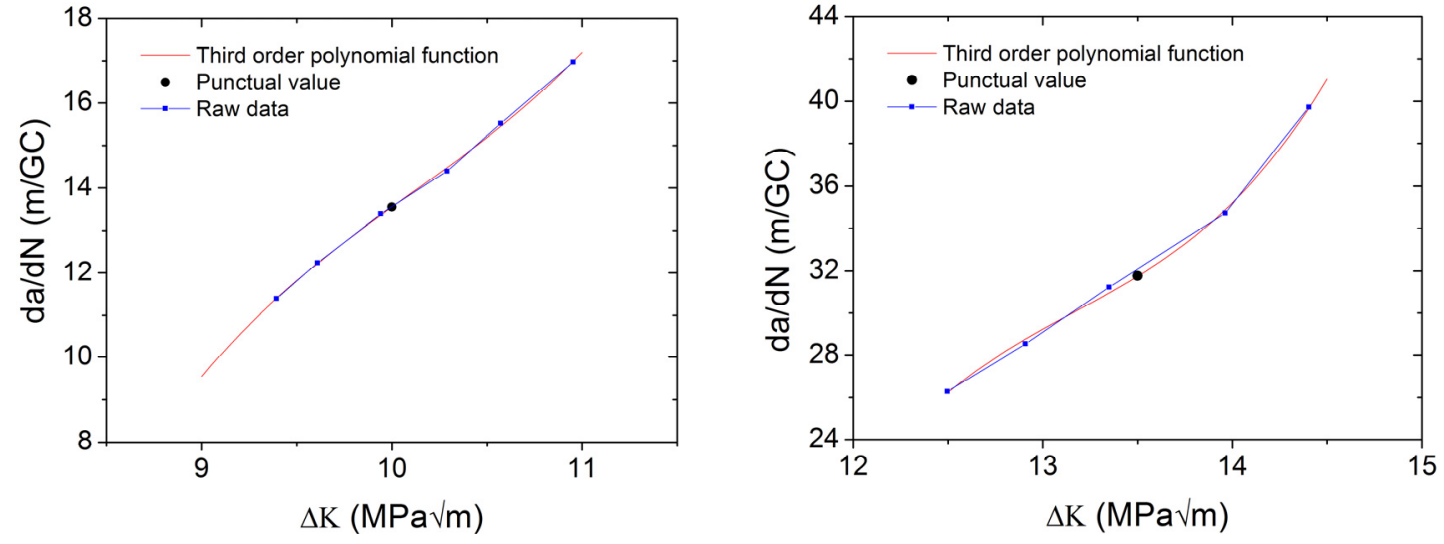

Figure 9: Third order polynomial fit of the crack growth rates.

\section{Procedure II}

In Fig. 10 fitting of the experimental data using the three-parameters model [11] is shown. The corresponding model parameters are reported in Tab. 4 together with the goodness-of-fit parameter $\mathrm{R}^{2}$.

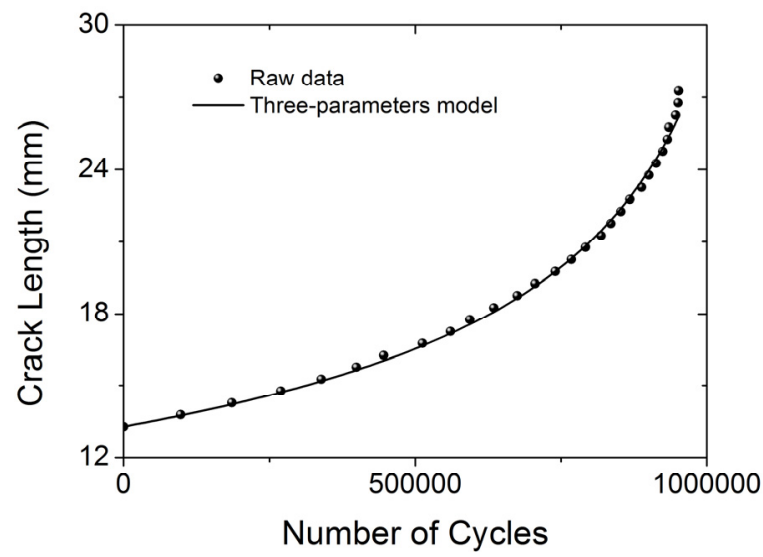

Figure 10: Raw crack growth data and three-parameters fitting function.

\begin{tabular}{cccc}
\hline$\alpha$ & $\beta$ & $\gamma$ & $\mathrm{R}^{2}$ \\
0.8283 & 0.3861 & $1 \mathrm{e}-04$ & 0.9992 \\
\hline
\end{tabular}

Table 4: Model parameters values (KDP_1 specimen).

By sampling the fitting function in the $\Delta \mathrm{K}$ ranges $9.5 \div 10.5 \mathrm{MPa} \sqrt{\mathrm{m}}_{\mathrm{m}} 13 \div 14 \mathrm{MPa} \sqrt{\mathrm{m}}$, pairs of values $\Delta \mathrm{K}-\mathrm{da} / \mathrm{dN}$ to be analysed by the procedure reported at the previous point are obtained. The corresponding crack growth rates are reported in Tab. 5 and diagrammed in Fig. 11 together with the crack propagation curves. From these diagrams it can be inferred that by the second and third order polynomial functions very similar goodness-of-fit are obtained.

\begin{tabular}{ccc}
\hline & $\begin{array}{c}\Delta \mathrm{K} \\
(\mathrm{MPa} \sqrt{\mathrm{m}})\end{array}$ & $\begin{array}{c}\mathrm{da} / \mathrm{dN} \\
(\mathrm{m} / \mathrm{GC})\end{array}$ \\
Second order polynomial function & 10 & 14.30 \\
Third order polynomial function & 13.5 & 31.65 \\
& 10 & 14.30 \\
\hline
\end{tabular}

Table 5: Crack growth rates computed using the procedure II. 

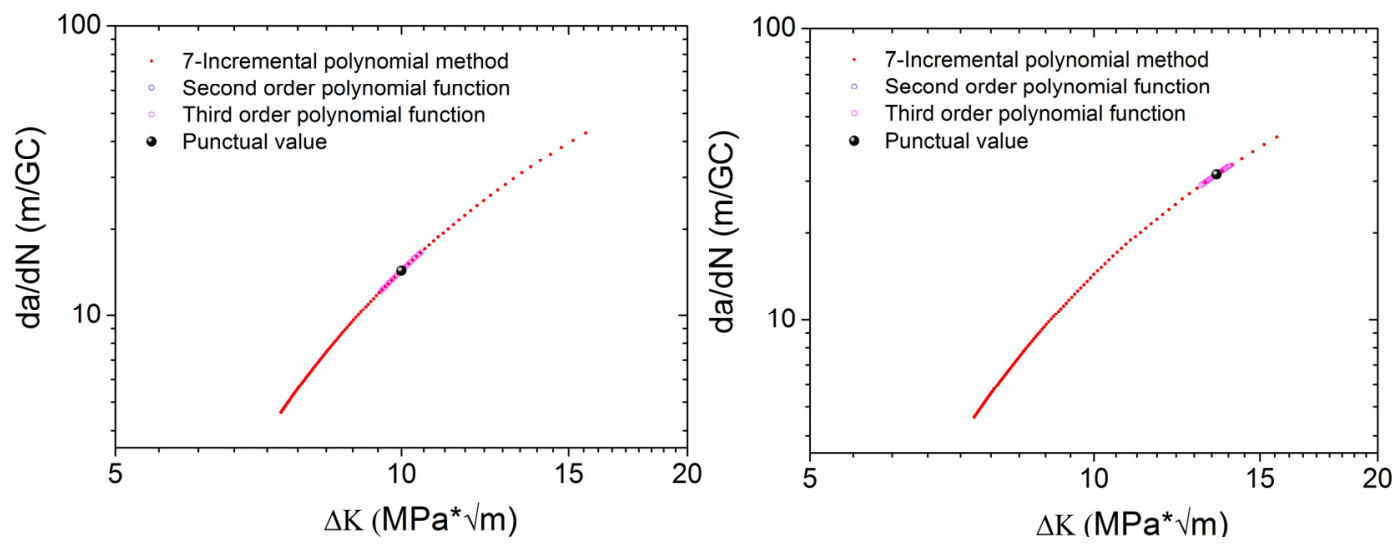

Figure 11: Crack propagation curves and local interpolation ranges.

\section{Procedure III}

Fatigue crack propagation curves, represented in Fig. 12, have been obtained computing the crack growth rates by the analytical expression of the derivative of the three-parameters model. In the same figure, the $\Delta \mathrm{K}$ ranges where interpolation by the second and third order polynomial functions is carried out are shown and the computed crack growth rates are diagrammed. These latter are reported in Tab. 6 as well.
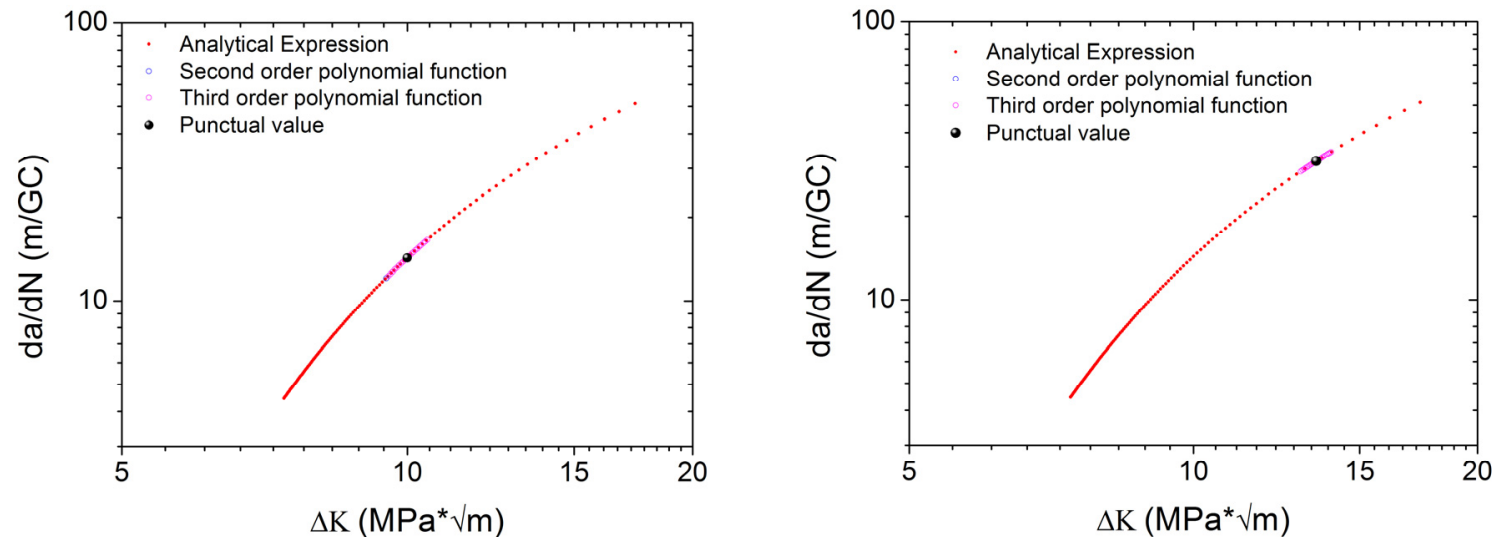

Figure 12: Crack propagation curves, local interpolation ranges and crack growth rate values.

\begin{tabular}{ccc}
\hline & $\begin{array}{c}\Delta \mathrm{K} \\
\left(\mathrm{MPa}^{*} \mathrm{~m}^{0.5}\right)\end{array}$ & $\begin{array}{c}\mathrm{da} / \mathrm{dN} \\
(\mathrm{m} / \mathrm{GC})\end{array}$ \\
Second order polynomial function & 10 & 14.28 \\
& 13.5 & 31.51 \\
Third order polynomial function & 10 & 14.28 \\
& 13.5 & 31.51 \\
\hline
\end{tabular}

Table 6: Crack growth rates computed using the procedure III.

\section{Procedure IV}

Fitting the experimental data, since $g(\alpha)$ has the following expression:

$$
\begin{aligned}
& g(\alpha)=\frac{6 \sqrt{\alpha}}{(1+2 \alpha)(1-\alpha)^{\frac{3}{2}}}\left[1.99-\alpha(1-\alpha)\left(2.15-3.93 \alpha+2.7 \alpha^{2}\right)\right] \\
& \alpha=\frac{a}{W}
\end{aligned}
$$


Being

$$
g(\alpha)=\frac{\Delta K \cdot B \cdot \sqrt{W}}{10^{1.5} \cdot \Delta F}
$$

It is possible to compute the $\alpha$ values corresponding to the reference $\Delta \mathrm{K}$ values, being known the applied $\Delta \mathrm{F}$ during the test and the specimen geometry, with which can be evaluated the crack growth rates reported in Tab. 7, using the Eq. (3) obtained from the model.

When to evaluate the crack lengths the following equation is used:

$$
\alpha=\frac{0.0004464 g(\alpha)^{3}+0.9019 g(\alpha)^{2}-6.597 g(\alpha)+11.7}{g(\alpha)^{2}-1.017 g(\alpha)-14.01}
$$

The crack growth rates reported in Tab. 8 are obtained.

\begin{tabular}{cc}
$\Delta \mathrm{K}$ & $\mathrm{da} / \mathrm{dN}$ \\
$(\mathrm{mPa} / \mathrm{G})$ & 13.79 \\
10 & 32.81 \\
13.5 & \\
\hline
\end{tabular}

Table 7: Crack growth rates computed using the procedure $I V$.

\begin{tabular}{cc}
$\Delta \mathrm{K}$ & $\mathrm{da} / \mathrm{dN}$ \\
$\left(\mathrm{MPa} \sqrt{\mathrm{m}}_{\mathrm{m}}\right.$ & $(\mathrm{m} / \mathrm{GC})$ \\
10 & 13.82 \\
13.5 & 32.84 \\
\hline
\end{tabular}

Table 8: Crack growth rates computed using the procedure $I V$.

\section{Procedure V}

In Fig. 13, the data points obtained analysing the raw data using the ASTM method together with the Paris model are reported.

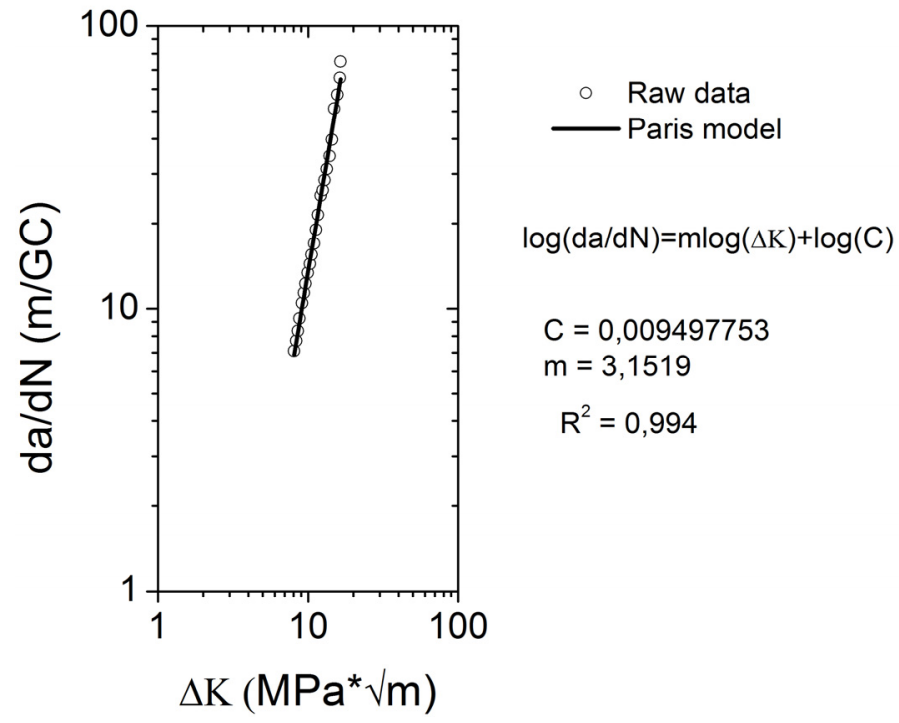

Figure 13: Crack propagation curves and Paris law.

In Tab. 9 the numerical crack growth rate values computed using the Paris model are given. 


\begin{tabular}{ccc}
\hline & $\begin{array}{c}\Delta \mathrm{K} \\
(\mathrm{MPa} \sqrt{\mathrm{m}})\end{array}$ & $\begin{array}{c}\mathrm{da} / \mathrm{dN} \\
(\mathrm{m} / \mathrm{GC})\end{array}$ \\
Paris & 10 & 13.48 \\
& 13.5 & 34.70 \\
\hline
\end{tabular}

Table 9: Crack growth rates computed using the procedure $V$.

All the crack growth rates computed using the discussed procedures are shown in Fig. 14 together with the fatigue crack propagation curves obtained analysing the experimental data by the procedure suggested by the ASTM [10].
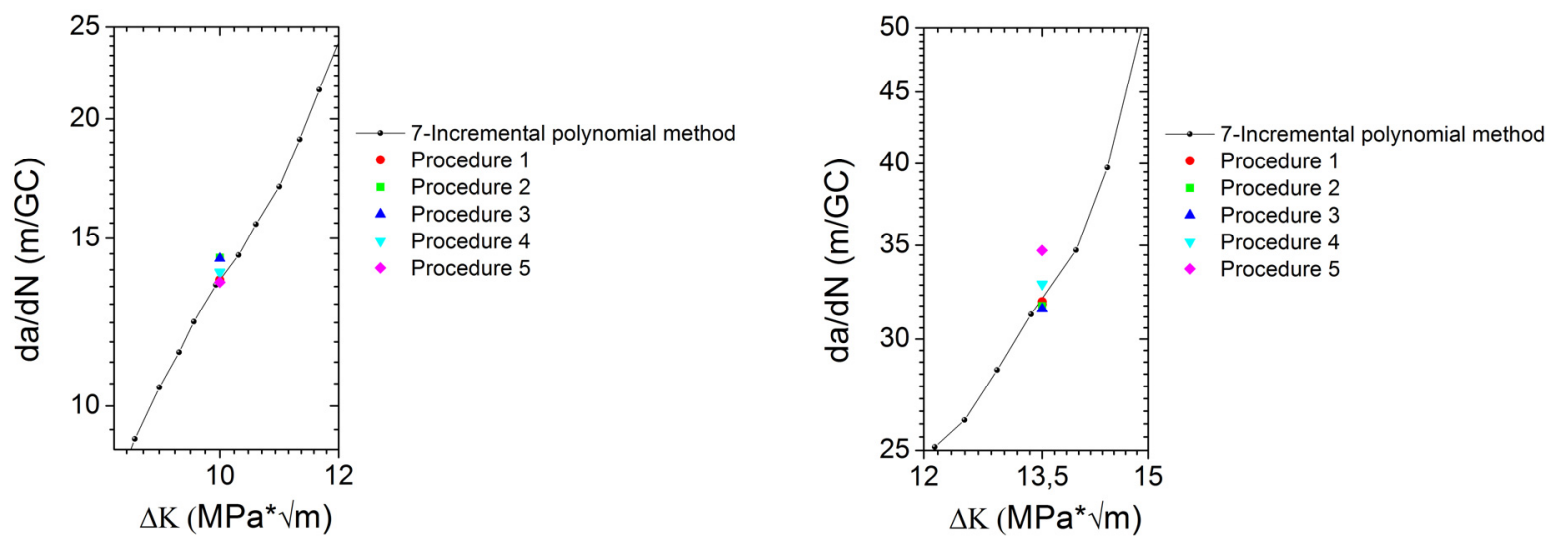

Figure 14: Comparison among crack growth rates corresponding to the different $\Delta \mathrm{K}$.

\begin{tabular}{|c|c|c|}
\hline $\begin{array}{c}\Delta \mathrm{K} \\
\left(\mathrm{MPa} \sqrt{\mathrm{m}}_{\mathrm{m}}\right)\end{array}$ & $\begin{array}{c}\mu \\
(\mathrm{MPa} \sqrt{\mathrm{m}})\end{array}$ & $\begin{array}{c}\Sigma \\
(\mathrm{MPa} \sqrt{\mathrm{m}})\end{array}$ \\
\hline 10 & 13.92 & 0.37 \\
\hline 13.5 & 32.26 & 1.05 \\
\hline
\end{tabular}

Table 10: Estimated crack growth rates: means and standard deviations.

Means and standard deviations of the crack growth rate estimates computed with the different procedures are given in Tab. 10 for several values of $\Delta \mathrm{K}$. The greatest deviation from the mean value occurs at the maximum $\Delta \mathrm{K}(13.5 \mathrm{MPa} \sqrt{\mathrm{m}})$. However, this result is essentially due to the excessive deviation of the value computed using the Paris model (see Fig. 14 right) from the crack propagation curve. For $\Delta \mathrm{K}=10 \mathrm{MPa} \sqrt{\mathrm{m}}_{\mathrm{m}}$ the maximum deviations occur for the procedure identified as I and II, probably due to the adoption of the three-parameters model to fit the experimental data points.

\section{CONCLUSIONS}

$\mathrm{D}$ uring the experimental activities carried out for the certification of rail steel, significant lacks in the current standard that regulates the principal tests arose. In the present paper the main results of the testing activities and the adopted procedures are reported. Also, the adopted choices in order to either implement the guidelines given by the reference Standards or to fill the aforementioned gaps left by these latter are described. In particular, due to the lacks in all current standards, some alternative procedures to compute the crack growth rates to be compared with the reference values prescribed by the standard have been proposed and verified. The final considerations about the obtained results represent a contribution to provide a mean for better understand and apply the current Standards to produce reliable results in the complex task of certifying a rail steel. 


\section{ACKNOWLEDGEMENTS}

he supply of materials by Manoir Industries Outreau (France) is greatly appreciated.

\section{REFERENCES}

[1] Jeong, D.Y., Correlations between rail defect growth data and engineering analyses, Part I: Laboratory tests, UIC/WEC Joint Research Project on Rail Defect Management. U.S. Department of Transportation (2003).

[2] Ravaee, R., Hassani, A., Fracture mechanics determinations of allowable crack size in railroad rails, J Fail. Anal. and Preven., 7 (2007) 305-310.

[3] Seo, J. W., Kwon, S. J., Lee, D. H., Kwon, S. T., Choi, H. Y., Fatigue crack growth and fracture behavior of rail steels, Int. J. of Railway, 5(3) (2013) 129-134.

[4] De Iorio, A., Grasso, M., Kotsikos, G., Penta, F., Pucillo, G. P., Development of predictive models for fatigue crack growth in rails, Key Engineering Materials, 488-489 (2012) 13-16.

[5] UNI EN 13674-1:2011, Railway applications - Track - Rail - Part 1: Vignole Railway Rails 46 kg/m and above.

[6] ISO 1099:2006, Metallic Materials - Fatigue Testing - Axial Force-Controlled method.

[7] ISO 12106:2003 Metallic materials - Fatigue testing - Axial-strain-controlled method.

[8] ASTM E399-09e2, Standard test method for linear-elastic plane-strain fracture toughness $\mathrm{K}_{\mathrm{Ic}}$ of metallic materials.

[9] BS-ISO 12108:2002, Metallic Material - Fatigue Testing - Fatigue crack growth method.

[10] ASTM E 647: Standard test method for measurement of fatigue crack growth rates, USA, (2011).

[11] De Iorio, A., Grasso, M., Penta, F., Pucillo, G.P., A three-parameter model for fatigue crack growth data analysis, Frattura ed Integrità Strutturale, 21 (2012) 21-29. 